\title{
IMPORTANT DISEASES OF COCONUT IN INDIA
}

\author{
K. K. N. Nambiar and Rohini Iyer ${ }^{1}$
}

\section{Introduction}

Today India stands at the third position as far as the world situation of coconut production is concerned. Coconut occupies 1.1. million hectares of land producing 6,887 million nuts in this country. In the southern part of the country viz. Kerala, Kamataka, Tamilnadu and Andhra Pradesh, coconut is a very good source of income and these states account for most of the production of coconut. In spite of the importance it has in India's economy, the productivity of the crop is low. Although many factors are responsible for the poor yields, the most important of these are the diseases that attack these palms and affect their productivity. Among these diseases, a few are killers while others are slow and debilitating in nature. For some of them the cause is known while the aetiology of some others is still elusive. This review envisages in discussing some of the recent research trends in the major diseases of coconut in India.

\section{Bud rot}

One of the most important killer diseases reported from almost all coconut growing tracts is bud rot. (Fig. 1 The first symptoms of the disease is the yellowing of one or two young leaves surrounding the spindle. The spindle withers and droops down. The tender tissues of the bases of young leaves and crown rot into slimy mass of decayed material emitting a foul smell. The disease affects palms of all ages; Seedlings and young palms being more susceptible than adult trees above 25 years. In the affected seedlings the spindle comes away on pulling. This disease spreads fast during the rainy season when low temperatures (minimum $21^{\circ} \mathrm{C}$ ) and high humidity $(97-100 \%)$ prevail.

Controlling the disease includes prophylactic measures and also curative treatments. When the disease is detected all the rotten and discoloured tissues should be chiselled, removed and burnt. Bordeaux paste (10\%) must be applied as wound dressing. This portion should be protected from rain by either covering with a polythene sheet or with an inverted bucket or pot. All trees around the affected palm should be sprayed with $1 \%$ Bordeaux mixture. The prophylactic measure includes spraying $1 \%$ Bordeaux mixture at the beginning of monsoon, especially for palms below 20-25 years.

\section{Root (wilt) disease}

Another notorious disease that has affected coconut in central and south Kerala is the Root (wilt) causing an annual loss of 968 million nuts. It is reported to have made its appearance since 1882 at three different places in central Kerala following severe floods. Recently the disease has been reported from Northern Kerala and some parts of Tamil Nadu, also. The svmptoms include

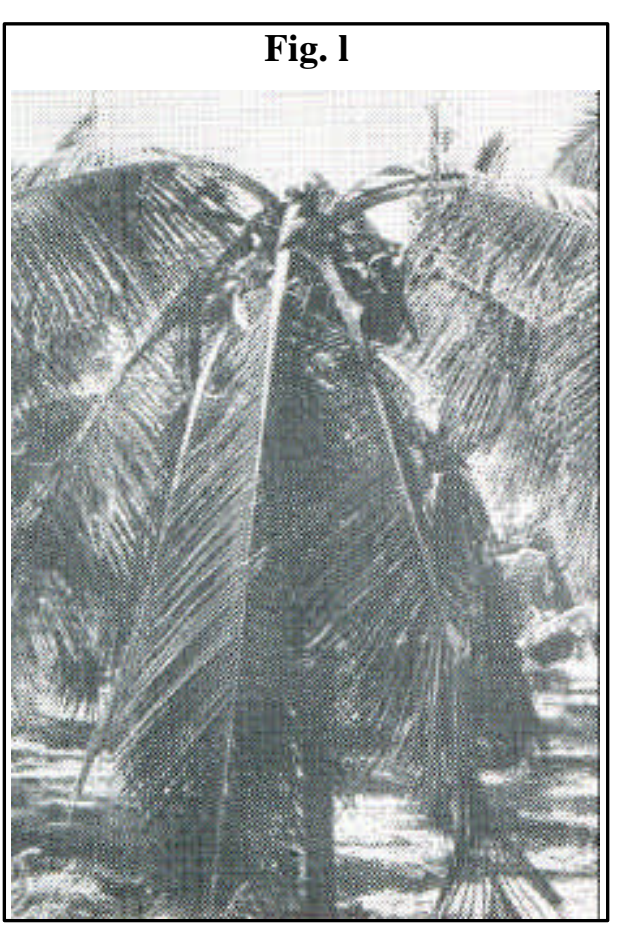

${ }^{1}$ Central Plantation Crops Research Institute Kasaragod - 670124, Kerala. 
flaccidity (bending of the leaflets to forrn a rib-cage like appearance), chlorosis of the older leaves and drying of the leaf-let margins (Fig. 2) Extensive root damage, shedding of buttons and immature nuts arc some of the associated symptoms. Extensive studies conducted earlier had shown that many biotic agents arc associated with the disease. But their exact role in the aetiolgy of the disease could not be determined. Recent studies in this direction has revealed that Mycoplasma like Organisms (MLO) arc consistently present in diseased leaves as evidenced by electron microscopic studies. Adults of a lace wing bug, Staphanitis typica, when given adequate acquisition and incubation periods are found to contain MLOs in the salivary glands. Studies indicate that dodder (Cassytha filiformis) can transmit the MLOs from diseased plant to an indicator plant Cataranthus roseus. Taking all these aspects into consideration, the weightage is currently in favour of MLOs as the causative agent of the disease.

Diagnostic tests based on scrology and stomatal resistance have been developed for early detection of the disease. These sensitive tests have been by and large helpful for detection of the disease in $75 \%$ of plants before visual symptoms are clearly manifested. Studies on the physiological aspects of the disease have shown that increase in respiration, deranged translocation and transport of sugars, altered nitrogen metabolism accompanied by amino acid accumulation (like Arginine) in the diseased palms occur consistently. The phenol content also drops down. Detailed nutritional studies conducted to determine the involvement of major and minor elements have brought out that there is no direct involuement of nutritional status on the incidence of the disease.

The root (wilt) disease is a slow debilitating malady. Measures for curative control of the disease are at present not available. Hence attempts on use of management practices that reduce the stress of the plant and help the

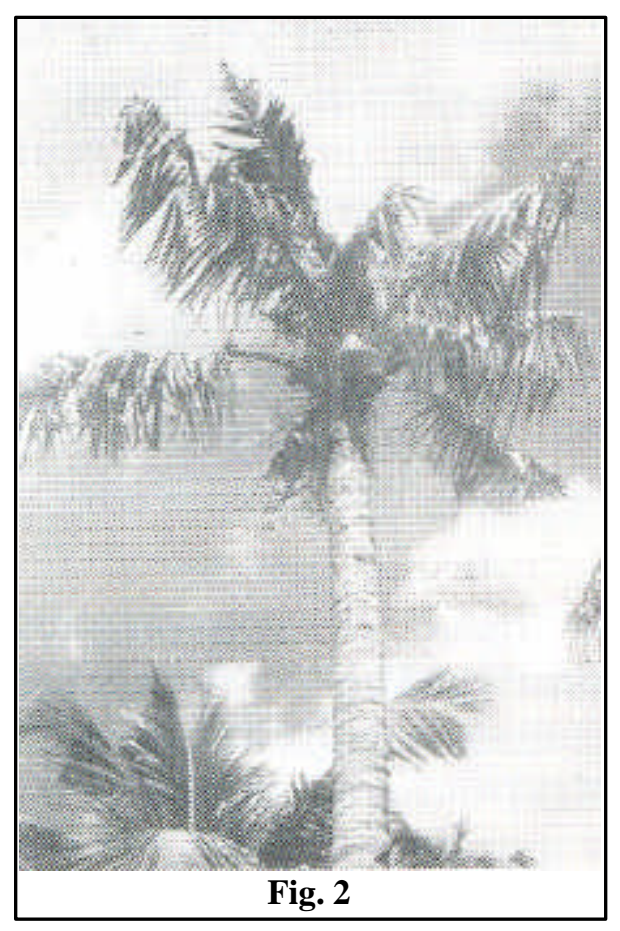
palms yields more, inspite of the disease, are now in progress. Evidence shows that aff6cted palms respond well to irrigation and fertilizer application. Yields of coconut were increased by $26.1 \%$ even though disease severity was unaffected in a mixed farming trial laid in diseased garden. In another trial it was found that cacao is a beneficial mixed crop in affected coconut garden under irrigation. The yield of coconut increased from 17.6 to 46 nuts per palm/year. Addition of leaf litter from cocoa helped to improve soil microflora. It has also been found that high yielding Chowghat Dwarf Orange $\mathrm{x}$ West Coast Tall (CDO x WCT) hybrids fared better in comparison to the parents in the root (wilt) affected tracts. At the $12^{\text {th }}$ year of planting, WCT had a cumulative yield of 266 nuts while CDO x WCT had 621 nuts. Varietal screening prograrnme involving cultivars and hybrids, both indigenous and exotic, is also in progress with a view to locating resistance to the disease.

Since root (wilt) affected palms are more prone to another disease (the leaf rot caused by Bipolaris halodes) it is imperative that in any control prograrnme of root (wilt), leaf rot control should also fmd a place. Symptorns of this disease include blackening and shrivelfing up of the distal ends of leaf lets in the central spindle and in some of the younger leaves. Later, the affected tissues fall off in bits, giving the infected leaves a fan shaped appearance with the midrib of the leaf projecting out. This disease can be controlled by regular plant protection sprays using $1 \%$ Bordeaux mixture, $0.3 \%$ Dithane M-45 and $0.5 \%$ copper oxychloride sequentially at quarterly intervals.

As the root (wilt) disease has been found to be slowly spreading, efforts have been made to contain the disease by repeated removal of the affected palms in the northern border zone (Trichur district) in the Kerala State. Studies on removal of the infection foci in mildly affected areas 
revealed that even after 14 years, there was no recurrence of the disease. Certain isolated pockets away from border areas also has clusters of diseased palms. Efforts are in progress to remove these also and contain the disease within the southern areas.

\section{Stem Bleeding :}

It is widely prevalent in many parts of India. It is caused by the fungus Thielaviopsis paradoxa (de Seynes) Von Hohnel, the pathogenecity of which has been conclusively proved by Indian workers very recently (Nambiar et al. in press).

Typical symptom of the disease is the development of dark patches on the stem accompanied by exudation of dark reddish brown fluid along the growth cracks. These may coalesce and form extensive areas of dark colour. Symptoms start near the base of the trunk (in most cases) or any portion of the trunk and gradually advance towards the crown. Symptoms aggravate during rainy season. On chiselling the affected portion, it is seen that only bark portion is affected (Fig. 3). Decay seldom proceeds inwards. However, in young palms under cooler moist conditions, the decay may extend to the centre. The external bleeding symptoms often do not indicate the extent of internal decay. Tissues beyond the point of external lesions are found to be discolored. As the stem symptoms aggravate, symptoms appear on the crown as well. Leaves of the outer whorl tum yellow rather prematurely, dry and droop down. Leaf size and consequently the crown size reduce. Nut production and nut fall is common. The softened bark tissue in the last stages, is affected by insects like Diocalandra and Xyleborus which make pin holes in the stem and thus aid faster deterioration of the coconut stem.

The causal organism is a weak pathogen. Hence growth cracks resulting from prolonged drought or soil moisture stress followed by sudden rains; etc., may pre-dispose the tree to infection. Other factors include water-logging, hard pan formation in the sub soil, poor nutritional status of soil and saline/alkaline soils.

In controlling the disease, phyto sanitation is the most important measure. When the disease is detected early the bark is chiselled Off taking care to remove all the decayed tissues. The infected tissue is to be burned and the wound protedted with hot coal tar or 10\% Bordeaux paste. Since Bordeaux paste is likely to be washed off during rains, coal tar is a better protectant. The affected trees should be isolated from the neighbouring palms by taking tranches 1 meter deep and $30 \mathrm{~cm}$ wide around the base at a distance of 2 meters from the trunk. Next important aspect is correcting the malnutrition by way of applying adequate

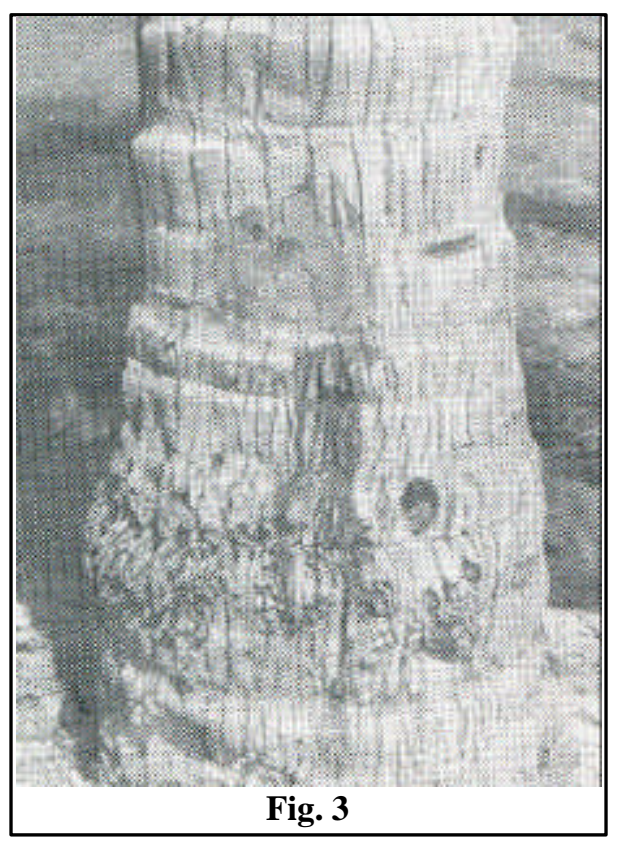
dose of fertilizers, and organics. The favourable effect of organic matter application has been noticed by many workers. Hence emphasis is given to organic matter application. In addition, application of $5 \mathrm{~kg}$ Neemcake/tree has been found to be beneficial. Another method of improving the organic matter status of the soil is by growing legumes in the basins as a cover crop and incorporating the biomass into the soil. Alleviating the moisture stress by giving irrigation during dry months is another important aspect of control. Providing drains during rainy season is also equally essential. If attack of secondary pests like Diocalandra and Xyleborus is noticed, the trunks of infected, palms should be swabbed with wettable BHC $(0.2 \%)$. Encouraging results have been obtained in preliminary trials by using Bavistin administered through roots. Further studies are in progress. In addition to these interim and immediate measures, a long term approach like breeding for resistance is to be thought off. 


\section{Thanjavur wilt/Genoderma disease of coconut}

This disease was first noticed in Thanjavur in Tamil Nadu state in 1952 after a devastating cyclone. Now this disease is wide spread in Tamil Nadu and also in the adjoining areas of Andhra Pradesh, Kamataka, and parts of Kerala Maharashtra, Guiarat and Orissa. This disease is also referred to as. 'Ganoderma root rot', 'Ganoderma wilt' or 'Anabe'.

Withering, yellowing and dropping of leaves of the outer whorl is the characteristic symptom. Slowly this advances to the inner whorls. In the soil, decay of fine roots is the early symptom. This gradually traverses upwards to the bole region. Exudation of Reddish brown viscous fluid from the base of the stem is seen. This may sometimes extend upto 3-4 meters height. By this time the palm would have been dead. Sometimes bracket like fructifications of the fungus (Ganoderma lucidum) is seen at the base of the tree (Fig. 4). Bracket formation is more common on dead stumps. However, it is not likely that ail the symptoms, will be present on the same tree at any given. time. There is wide variation in the symptom expression and severity. As the palm deteriorates, leaves dry and hang down; nuts fall and the decline is hastened. There is reduction in the leaf size and consequent reduction in crown size. The exposed crown tissues arc easily attacked by softrotting bacteria and fungi and this results in weakening of the crown which may get blown off by wind.

Ganoderm lucidum is found very closely associated with diseased palms in many regions and hence is a strong suspect as a pathogen. However Koch's postulates are yet to be proved.

It has been. observed that palms in the age group of ten to thirty years arc more prone to the disease. Disease incidence is more in coastal sandy or sandy loam soils. Incidence of the disease is high where plants arc subjected to fluctuating moisture regions like flooding during rains interspersed wim the long dry spells in summer.

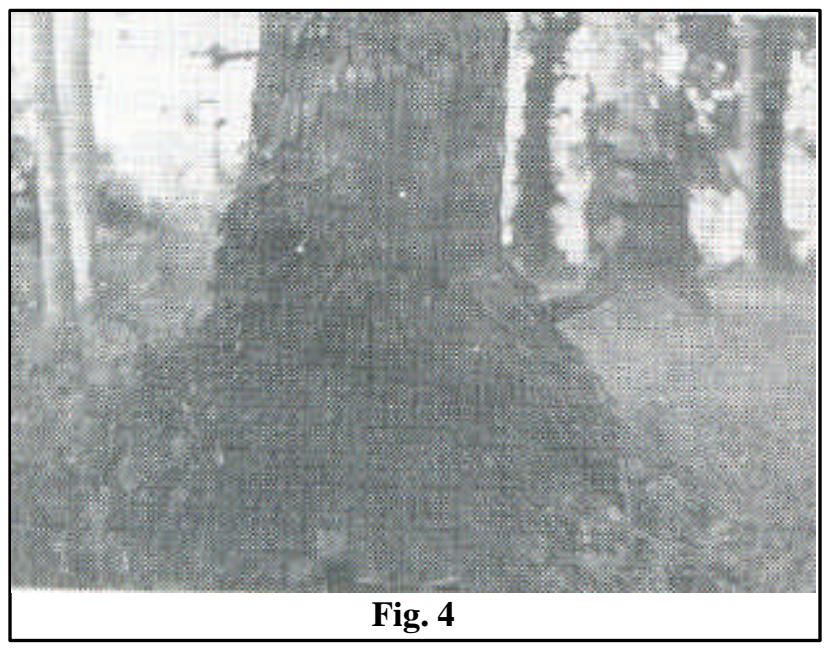

Normally the disease spreads like a typical soil borne disease, in a centrifugal fashion. The spread becomes faster when the basins are flooded or irrigation channels are through the palm rows. Similarly repeated ploughing was also found to hasten the disease spread.

Controlling the disease has to be achieved by adopting integrated. measures. Destroying all unproductive and severely affected palms along with the bole and roots is a must in preventing further spread of the disease. Tissues showing stem bleeding should be chiselled, destroyed and the wound dressed with hot coal tar or $10 \%$ Bordeaux paste. In case damage is deep-seated the affected portion may be scooped off and the cavity protected as above and then filled with cement for reinforcing the trunk. Affected palms should be isolated by trenches (1 Meter deep and $30 \mathrm{~cm}$ wide) dug at 2 meter radius around the affected tree. Another circle of trench should be taken to include the next apparently healthy palms around the diseased palm. These trenches should be soaked with fungicides like $1 \%$ Bordeaux mixture or $0.3 \%$ captan. Irregular planting and closer spacing should be avoided in coconut gardens. Soil moisture stress should be reduced by facilitating drainage during rainy season and adequate irrigation during summer. Irrigation channels should be taken between rows and individual sub channels should be provided to feed coconuts on either side. Drip irrigation may be resorted to wherever possible. When mixed cropping is planned, planting of Ganoderma-resistant plants like Banana and Ailanthus may be included as component crops. Palms 
should be given adequate amount of nutrients. Organic matter content of the soil could be improved by addition of compost, farm yard manure green leaves or tank silt. In addition to these, $5 \mathrm{~kg}$ neem cake/tree/year may be applied during September every year. The diseased palm may be treated with Aureofunginsol + copper sulphate at the rate of $2 \mathrm{~g}+1 \mathrm{~g}$ in $100 \mathrm{ml}$ water through root feeding thrice a year (in July, October and January). The attack by Xyleborusl Diocalandra when noticed may also be checked by appropriate remedial measures (Swabbing with $0.2 \%$ BHC Wettable powder). Care should be exercised not to use seedlings from endemic areas.

\section{Tatipaka disease}

This disease assumed importance after a heavy cyclone that swept Andhra Pradesh in 1949. It was first noticed in Tatipaka Ulage of East Godavari district of Andhra Pradesh and hence its name. Important symptoms of the disease are root rotting, reduction in number and size of leaves and leaf-lets, chlorotic water soaked svots on lamina. Dale green color of foliage, abnormal bending 'of fronds, fasciation of leaflets, abrupt tapering of stem, (Fig. 5) formation of small inflorescences with atrophied nuts ultimately resulting in barrenness of the tree. The extent of atrophy varies from losing the tricarpellary shape and size reduction of nuts to total absence of endocarp and endosperm.

Investigations have been going on for the past 25 years to find out the aetiology of the disease. Indirect evidences point towards a mycoplasmal actiology. Thus the affected palms were found to slightly respond to stem injection of tetracycline hydrochloride @ 3g/palm. Electron microscopy of the tissues of the affected palms also revealed MLOs in them. Further work in this line is in progress.

Since this disease is endemic to a small pocket in East Godavari district in Andhra Pradesh, efforts are on way to contain the disease within that area. Replanting old, unproductive and heavily diseased palms is suggested. Palms having mild to moderate disease intensity responded, favourably to measures taken for root regeneration. Application of fertilizers, Magnesium Sulphate, Farm Yard Manure and river silt favoured production of new roots and irnproved the condition of the palms.

\section{Crown choking disease}

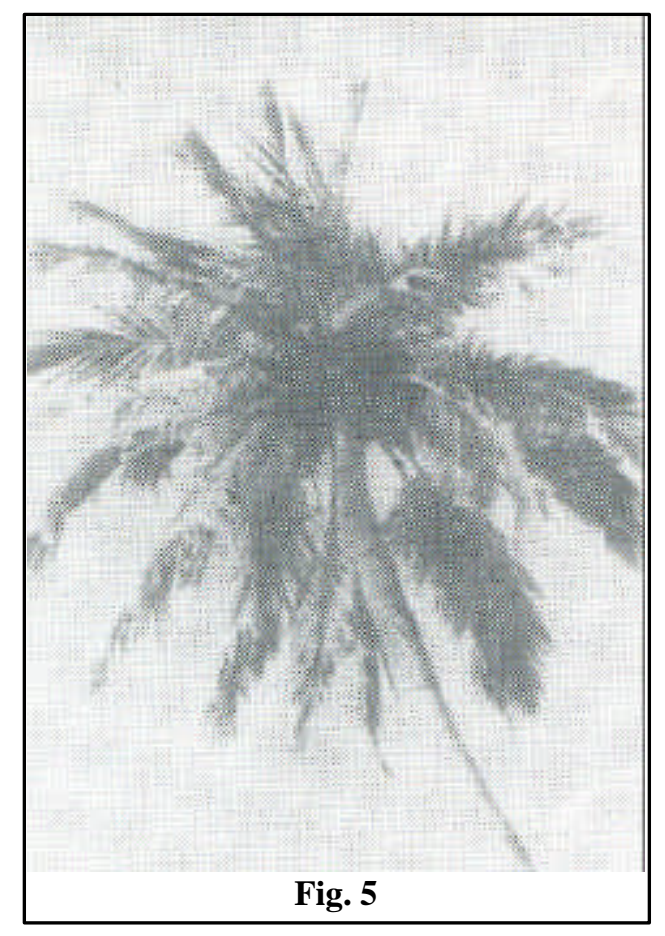

This disorder was first noticed in 1964 at Kahikuchi is Assam. Later this disease was found to exist in other parts of Assam and parts of West Bengal also. Young palms of 3-6 years of age are more susceptible and exhibit the symptoms more frequently than adult palms. Early symptom of the disease is emergence of shorter leaves with deformed and crinkled leaf-lets. These are affected by severe tip necrosis and their number decreases progressively when the attack is acute. The affected leaflets fail to unfurl, giving a choked appearence to the frond. As the disease progresses, severely necrotic, black, stick like leaf-stalk devoid or any leaflet emerges. In acute cases the peripheral leaves crowd around the bud and prevent unfurling of the flag-leaf. The productivity of the palms is affected.

In very severe cases, necrosis of the primordial tissue takes place and the crown dies. Stem does not taper below the crown. Death of affected palm is gradual and the palm loses vitality and finally succumbs within 3-4 years. Boron deficiency is found to be associated with the disease. 
It was found by Chakkravarthy et al (1970) that application of Borax @ 50g/palm to the coconut basin resulted in recovery of the affected palms (Fig. 6). Releasing the pressure exerted by the crowded leaves by removing one or two tightly placed leaf-speaths was also found to be beneficial.

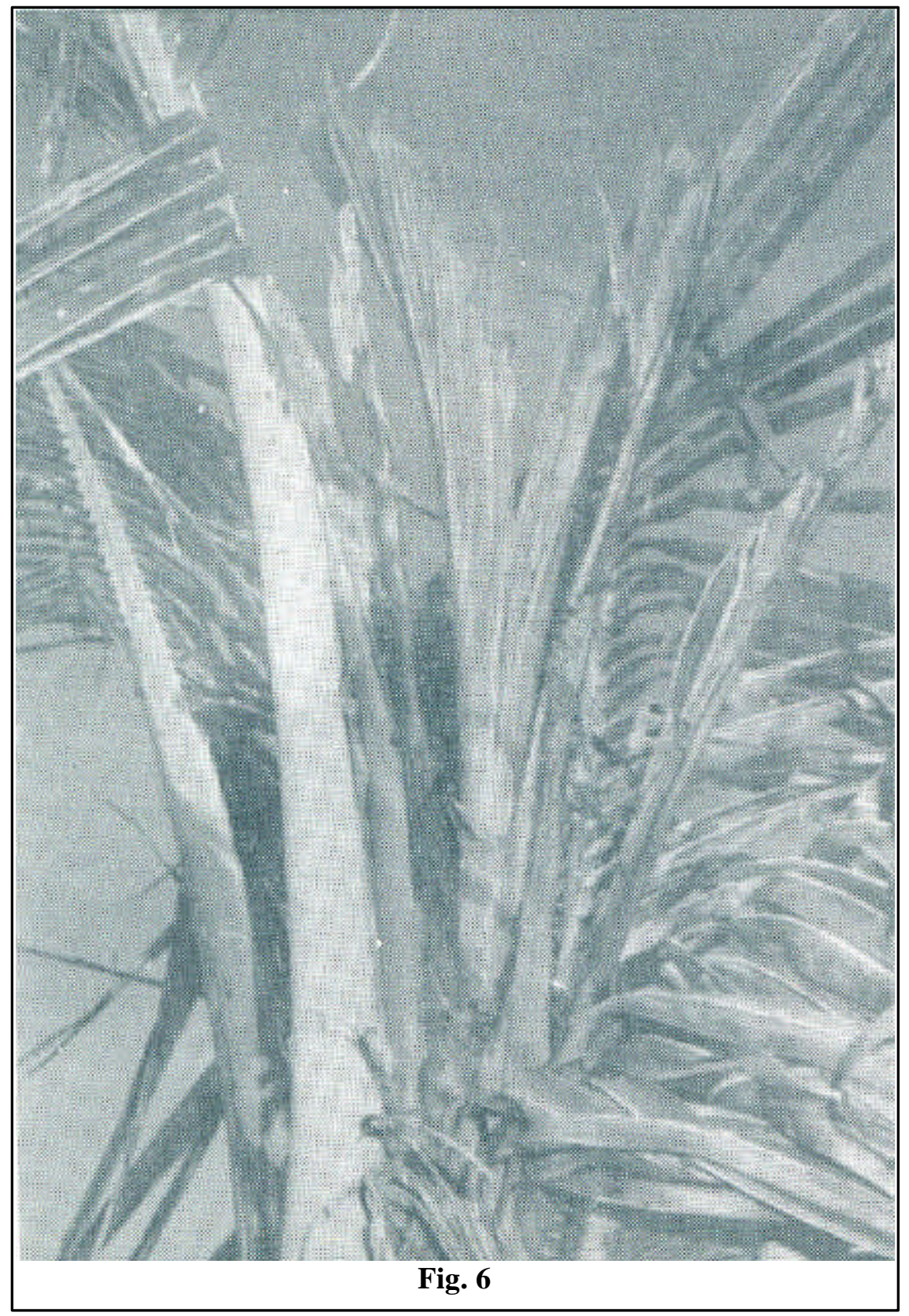




\section{REFERENCES}

1. ANON, 1986. Coconut root wilt disease - Present status of research management. Technical Bulletin No. 14 : CPCRI, Kasaragod 670 124, pp. 10.

2. ANON, 1986. Thanjavur wilt/Ganoderma disease of coconut. Pamphlet No. 30: CPCRI, Kasaragod 670 124, pp. 10.

3. CHAKRAVARTHY, B. K., NATH, B. K., \& GOSWAMY, M. N. 1970. Note on crown rot disease of coconut. Indian Journal of Agricultural Science 40 : 502-4.

4. CHAKRAVARTHY, B. K., NATH, B. K. \& GOSWAMY R. N. 1972. Correct frond bending of coconut by surgery. Coconut Bulletin 3 (7):5-6.

5. JAYASANKAR, N. P. \& AHAMED BAVAPPA, K. V. 1986. Coconut root (wilt) disease Past studies, present status and future strategy. Indian Journal of Agricultural Sciences 56 (5):309-28.

6. MENON, K P V and PANDALAI, K. M. 1960. The coconut palm A monograph. Published by Indian Central Coconut Committee pp 384.

7. NAMBIAR, K K N., YATEENDRA JOSHI, MN VENUGOPAL and R C MOHAN (in Press). Stern bleeding disease of coconut : Reproduction of symptorns by inoculation with Thielaviopin paradoxa.

8. PANDIT, S. V., SHIMHACHLAM S V., and LAL, S B 1968. A note on 'Tatipaka' or decline disease of coconuts in Andhra Pradesh, India. Paper $3^{\text {rd }}$ Session FAO Tech. Wkg. Pty. Cocon. Prod. Bot. and Processg., Jogjakarta, -1 -2.

9. RADHA, K., AND THOMAS JOSEPH 1974. Investigations on the budrot disease Phytophthora palmivora (Butl.) of coconut final report PL480 project 1968-73. pp.32.

10. RETHINAM, P. 1987. Management of Ganoderma wilt disease in palms. Paper presented at the International Symposium on Ganoderman wilt diseases on palms and other perennial crops (ISOGAWD) 6-8 January, 1987.

11. VENKATAKRISHNAIAH, N S., 1956. Anabe roga of coconut and arecanut palms caused by Ganoderma lucidum and its eradication Mysore agric. J. 31:277 -281. 